Research Article

\title{
Determinants of the Use of Hermetic Storage Bags for Maize Storage among Smallholder Farmers in Northwest Ethiopia
}

\author{
Tigist Kefale Mekonen ${ }^{1}{ }^{1}$ and Biruk Yazie Wubetie $\mathbb{D}^{2}$ \\ ${ }^{1}$ College of Agriculture and Natural Resources, Debre Markos University, Debre Markos, Ethiopia \\ ${ }^{2}$ College of Agriculture and Environmental Science, Bahir Dar University, Bahir Dar, Ethiopia
}

Correspondence should be addressed to Biruk Yazie Wubetie; birukyazie@gmail.com

Received 25 November 2020; Accepted 25 August 2021; Published 10 September 2021

Academic Editor: Volkan Okatan

Copyright (c) 2021 Tigist Kefale Mekonen and Biruk Yazie Wubetie. This is an open access article distributed under the Creative Commons Attribution License, which permits unrestricted use, distribution, and reproduction in any medium, provided the original work is properly cited.

\begin{abstract}
In Ethiopia, postharvest losses, mainly storage losses by insects, are very critical problems in agricultural production systems. In particular, maize is highly susceptible to insect and pest attacks in the storage. These storage losses affect the livelihood of smallscale farmers by aggravating their food insecurity and reducing their household income. This critical problem forced the farmers to look forward modern storage technologies like Purdue improved crop storage (PICS) bags, but its adoption is considerably low in the study area. Therefore, the objectives of this study were to examine the determinants to use PICS bags for maize storage. Data were collected through semistructured questionnaire, group discussion, key informants, and direct observation. A total of 392 sample household heads were selected by simple random sampling techniques. Binary logistic regression model, descriptive statistics, and inferential statistics were employed to analyze the data. This study revealed that, about $58 \%$ of the respondents replied that the importance of PICS bags in reducing insect damage was high. The results of binary logit model also indicated that educational level, sex, awareness, training, accessibility, perception on the effect of pesticide, social responsibility, and total income of the household positively and significantly affect farmers' decision to use PICS bags. Moreover, the price of PICS affects negatively and significantly. Therefore, policy makers have to give emphasis for this newly introduced storage technology to address storage loss problems by taking in to account these determinants.
\end{abstract}

\section{Background}

Purdue Improved Cowpea Storage technology was first developed by Purdue University/IRAD-Cameroon Cowpea Storage Project in the late 1980s by Professor Larry Murdock and his team, with support from the Bill and Melinda Gates Foundation [1]. This technology was originally created until the trademark "Purdue Improved Cowpea Storage" (PICS) for West and Central African cowpea farmers to protect against extremely destructive cowpea bruchids, which prevented resource-constrained farmers from long-term storage to capture price increases later in the marketing season. Around the end of 2013, SG-2000 Ethiopia began working with Purdue University to get a local manufacturer for PICS bags established in Ethiopia, and 5,000 PICS bags were manufactured in the country. Beginning in September 2015,
SG-2000 Ethiopia started implementation of the PICS-3 project after signing a one-year agreement with Purdue University. Plan of the project was to implement PICS bags in 2,200 villages. However, due to high demand and requests from government partner organizations, especially the Regional Agriculture and Natural Resource Bureaus, 3,155 villages have now been reached by SG-2000 Ethiopia. Those villages are located in 31 districts of 5 regional states of Ethiopia including Amhara, Benishangul Gumuz, Oromia, SNNP, and Tigray.

Food and Agriculture Organization of United Nations (FAO) predicts that, about 1.3 billion tons of food are globally wasted or lost per year [2]. Reduction in these losses would increase the amount of food available for human consumption and enhance global food security. Various studies undertaken in Sub-Saharan Africa to estimate maize 
grain losses in traditional storage practices have shown that the losses are very high such that, from harvest to consumer market, its losses are estimated to range from 14 to $36 \%$ [3]. One in five $\mathrm{kg}$ of grain produce in Sub-Saharan Africa is estimated to be lost by pest infestations and associated grain decays in which maize grain loss remained the highest [2].

In Ethiopia, the number of food insecure population remains unacceptably high each year; however, massive quantities of food are lost due to spoilage and infestations on the journey to consumers. Losses may occur for two main reasons. During harvesting, handling, processing, and transport grain may be scattered, dispersed, or crushed. Alternatively, the grain may be subject to biodeterioration. A study conducted in three major grain producing areas of Ethiopia, viz., Hetosa, Ada, and Bako, indicated that a majority of farmers $(93.3 \%)$ are using various traditional grain storage containers that expose their stored grains to be attacked by storage pests and other factors that contribute to deteriorations whereby per household grain $12 \%$ was estimated from the total grain produced [4]. To fight those storage pests, many extension offices promote pest management strategies such as insecticide use and/or solar disinfection, though certain botanicals show moderate potential as storage treatments [5]. However, the low effectiveness of botanical and/ or solar disinfection forced the community to look forward to a new technology (PICS) $[6,7]$. Therefore, this study attempts to examine the perception of farmers towards PICS bags and identify the determinants of the use of this PICS bags to store maize (Figure 1).

1.1. Conceptual Framework. The conceptual framework of the study is shown in Figure 1.

\section{Methods}

2.1. Description of the Study Area. Burie is one of the districts of Amhara National Regional State, Northwest Ethiopia. It is located between latitude $10^{\circ} 17^{\prime}-10^{\circ} 49^{\prime}$ north and longitude $37^{\circ} 00^{\prime}-37^{\circ} 11^{\prime}$ east (Figure 2). It is $400 \mathrm{~km}$ away in the northwest of Addis Ababa and $148 \mathrm{~km}$ southwest of Bahir Dar, the regional state capital. Agroecologically, the district is classified into highland (1\%), midland (77\%), and lowland (22\%) [9]. Maize is one of the stable crops in the study area.

2.2. Data Collection Methods. Both relevant qualitative and quantitative data were collected from primary and secondary sources. The data were collected from household heads mainly through semistructured questionnaire. The questionnaire translated into local Amharic (local language) to ease the data collection process. Next to this, the questionnaire was pretested before conducting formal survey and amended based on the feedback obtained. To do this, $5 \%$ (20 households) of the sample respondents were randomly selected from other districts which have similar socioeconomic conditions with the study area. Then, ten enumerators were recruited and trained for two days on the method of data

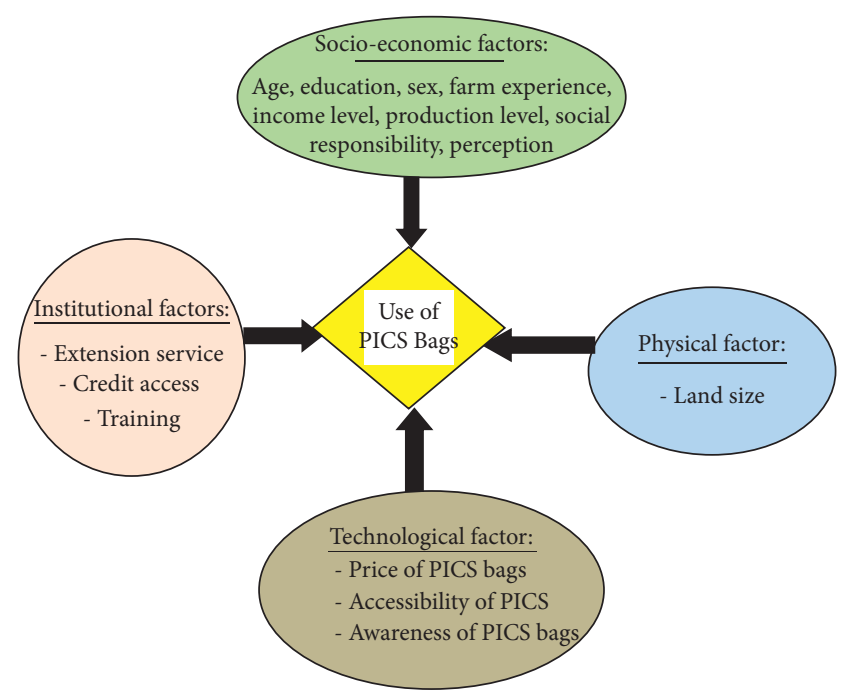

FIgURE 1: Conceptual framework of the study.

collection and related topics. The enumerators gather the required data under the close supervision of the researcher. The objective of the study and confidentiality of the respondents' information was explained to the respondents before interview. Focus group discussions, key informant interview, and direct observation were also used as methods of data collection for this investigation.

2.3. Sampling Procedure and Sample Size. The study was conducted in Burie district because it is the project site and the PICS storage technology is already introduced and farmers are using this technology. This study was employed multistage sampling frame. From 22 rural kebeles, there are 14 PICS user kebeles in the district, and then, three kebeles, namely, Zalima, Wadra, and Gulim were selected through simple random sampling techniques. Households in the selected kebeles were stratified as users and nonusers of PICS bag. The sample size is determined by using Yamane formula [10] at $95 \%$ confidence level and 5\% precision level. This formula is applied to get more sample size which is representative for the population:

$$
n=\frac{N}{1+N(e)^{2}}
$$

where $n$ is the sample rural household, $N$ is the total household size, and $e$ is the level of precision. Lastly, 392 sample household heads were selected randomly from both strata by probability proportional to the size of each kebele and stratum.

2.4. Data Analysis Methods. The data were analyzed by using descriptive statistics (percentage, frequency, mean, minimum, maximum, and standard deviation), inferential statistics ( $T$-test and chi-square test), and binary logistic regression model through SPSS version 23 software. Charts, graphs, and tables were used to present the data. 


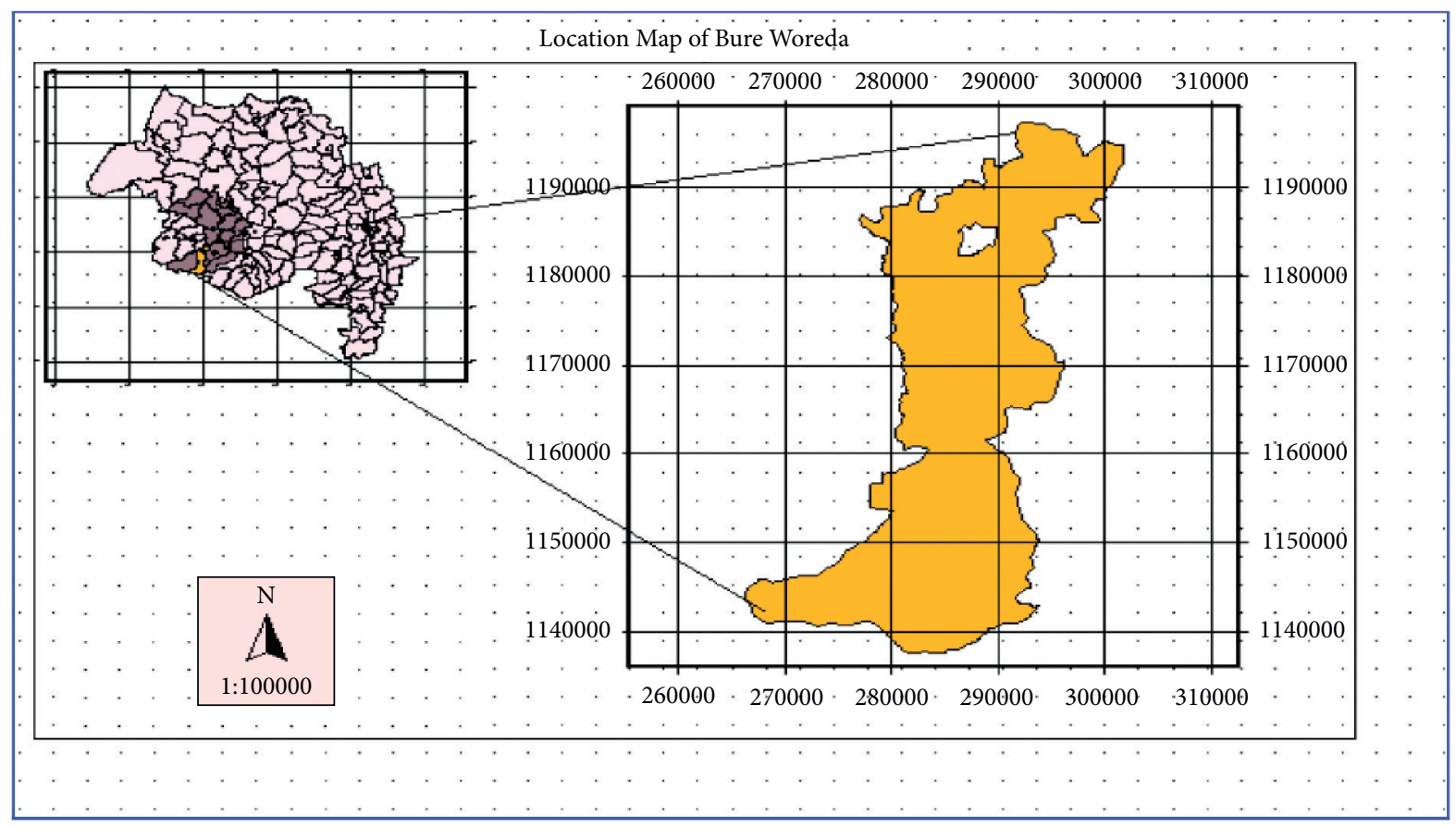

Bure Woreda West Gojjam Zone Amhara Region

Figure 2: Location map of the study area. Source: adopted from Aleminew [8].

2.4.1. Binary Logistic Regression Model. Logistic regression has got advantage over others in the analysis of dichotomous outcome variables i.e., users and nonusers of PICS bags. There are two primary reasons for choosing the logistic distribution. These are (1) from a mechanical point of view, it is an extremely flexible and easily used function, and (2) it lends itself to a meaningful interpretation. The logit model is simpler in estimation than the probit model [11-13]. Therefore, a binary logistic regression model was used to study the decision behavior of sampled households, and why binary is because the dependent variable (farmers' decision/preference on storage structure-PICS storage structure versus conventional storage structure) has the nature of dichotomous or binary responses. Following Gujarati [14], the logistic distribution function for identification of households' decision to use PICS bags for maize storage can be defined as

$$
P i=E\left(Y=\frac{1}{X i}\right)=\frac{1}{1+e^{-\left(\beta_{0}+\beta_{1} X_{1}+\beta_{2} X_{2}+\cdots+\beta m X m\right)}} .
$$

Since $Z_{i}=\beta_{0}+\beta_{1} X_{1}+\beta_{2} X_{2}+\cdots+\beta m X m$, the above formula can be rewrite as shown for easy understanding:

$$
P i=\frac{1}{1+e^{-Z_{i}}}=\frac{e^{Z_{i}}}{1+e^{Z_{i}}} .
$$

The above formula indicates that, as the value of $Z_{i}$ ranges from negative infinitive to positive infinitive $P i$, the probability of households' decision to use PICS storage ranged between 0 and 1 . Therefore, when $P i$ is the probability of household's to use PICS bags, then $(1-P i)$ will be the probability of households not to use PICS bags. This can be represented as follows:

$$
1-P i=\frac{1}{1+e^{Z_{i}}} .
$$

Now, the most important element in the logistic regression, i.e., odds ratio, can be obtained from equations (3) and (4) which is represented as $P i / 1-P i$ as shown in the following expression:

$$
\frac{P i}{1-P i}=\frac{1+e^{Z_{i}}}{1+e^{-Z_{i}}}=e^{Z_{i}} .
$$

The odds ratio in logistic model shows the extent or degree of favoring the household's decision to use PICS maize storage structures. When we take the natural logarithm of equation (5), we can obtain the following formula for logit model which is mostly represented as

$$
L i: L i=\ln \left(\frac{P i}{1-P i}\right)=Z_{i}=\beta_{0}+\beta_{1} X_{1}+\beta_{2} X_{2}+\cdots+\beta m X m .
$$

Then, if the disturbance term $U i$ is taken in to account, the logit model becomes 


$$
Z_{i}=\beta_{0}+\sum_{i=1}^{m} \beta i X i+U i
$$

where $\beta_{0}=$ the intercept. It is the value of the log odd ratio $P i / 1-P i$, when $X$ or explanatory variable is zero. $\beta_{1}=$ the slope, measures the change in $L$ (logit) for a unit change in explanatory variables $(X)$. Before running the binary logistic regression model, multicollinearity among the explanatory variables was checked. According to [13], continuous variables variance inflating factor (VIF) and condition index (CI) and discrete variables coefficient of contingency (CC) were employed to check the colinearity effects among the variables. A VIF value greater than 10 and CC value greater than 0.75 is used as a signal for a strong multicollinearity [13].

\subsection{Definition of Variables}

2.5.1. Dependent Variable. The dependent variable of the study has dichotomous nature which represents the observed use of PICS bags. It was represented in the model as yes $=1$ for the household that uses PICS bags and no $=0$ for household that did not use PICS bags.

2.5.2. Independent Variables. Based on the review of literature, the past research findings, and the researcher's knowledge of the storage system of the study area, 15 potential explanatory variables were considered in this study and examined for their effect in farmers' use of PICS bags (Table 1).

\section{Results and Discussion}

3.1. Socioeconomic and Demographic Characteristics of Sample Households. Tables 2 and 3 present the socioeconomic and demographic characteristics of respondents with categorical and continuous variables which are analyzed by descriptive and inferential statistics. The survey result indicated that, among the total sample household heads, $93.8 \%$ were male and $6.2 \%$ of them were female. The marital status of household heads showed that $0,3 \%, 92.9 \%, 2.3 \%$, and $4.6 \%$ of them were single, married, divorced, and widowed, respectively. Likewise, $96.4 \%$ of users and $91.3 \%$ of nonusers were male. About $95.9 \%$ of users and $89.8 \%$ of nonusers were married (Table 2). The chi-square test for sex and marital status distribution between the two groups was found to be significant at $5 \%$ probability level. The education level of household heads is expected to increase the ability to obtain, process, and use information relevant to the use of improved agricultural technologies in general and Purdue improved crop storage bags/technologies in particular. The survey results indicated that, about $49.7 \%$ of the total respondents are illiterates (cannot read and write), while the rest $50.3 \%$ of the respondents had various educational levels ranging from the ability to read and write up to secondary education and above. As shown in Table 2, about $23 \%$ of users and $76.5 \%$ nonusers were illiterate farmers.
The study revealed that farmers who had higher education level show eagerness to grasp new ideas and to try the technology by allocating some of the scarce resources. The result of $\chi^{2}$-test showed significant difference for the distribution of illiterate and educated household heads of the two groups.

The average age was found to be 45.23 ranging from 26 to 72 years with a standard deviation of 8.803 . Reported that the average age of the household head was about 45 years at the national level which is closely similar to the result of this study. The mean age of users and nonusers of Purdue improved crop storage technologies is 42.68 and 47.78 years with a standard deviation of 6.792 and 9.816, respectively (Table 3). The mean age of users was found to be less than that of nonusers. The result of $t$ test showed that the mean difference of two groups was significant at $1 \%$ probability level. Family size refers to the number of individuals who live in the same house having common goal for a minimum of six months. The family size of the sample households ranges from 1 person to 9 people, with a mean of 4.98 people and a standard deviation of 1.562 . The above result is higher than the regional average household size (4.6) [15]. The average family size of users and nonusers was found to be 4.99 and 4.96 people with a standard deviation of 1.625 and 1.5 , respectively. The statistical analysis showed that the difference in the mean family size between users and nonusers is insignificant.

The average years of farming experience for the total sample household heads, users, and nonusers were found to be $23.41,21.17$, and 25.64 years with a standard deviation of $8.087,6.633$, and 8.780 , respectively. The farming experience ranges from 4 to 45 years for sample household heads. The mean number of years of experience of the nonusers was found to be greater than that of users (Table 3). Statistically significant difference was observed between the two groups with respect to the mean farming years of experience. It may be because older farmers are reluctant to new emerging technologies. The survey results showed that landholding size of total sample households ranges from 0.25 to 7 ha with a mean of 2.25 ha and standard deviation of 1.26 . The average landholding size of users and nonusers were 2.38 and 2.11 ha with a standard deviation of 1.22 and 1.30 , respectively. The result of $t$ test showed that the mean landholding size difference between the two groups was significant (Table 3).

Farm animals also serve as a measure of wealth in the rural area. Cattle, sheep, goats, and poultry are important species of livestock kept by the farmers in the area. In line with the above explanation, livestock ownership of the respondents was measured using the tropical livestock unit (TLU). To help the standardization of the analysis, the livestock number was converted to tropical livestock unit (TLU). The average size of livestock in TLU was found to be $6.16,7.3$, and 5.02 for total sample households, users, and nonusers with a standard deviation of $2.69,2.58$, and 2.30 , respectively (Table 3 ). This result is higher than the regional average (3.87 TLU) and the national average of 4.46 TLU. This result indicated that the livestock ownership of user households was greater than the total 
TABle 1: Definition and units of measurement for explanatory variables.

\begin{tabular}{|c|c|c|}
\hline Variables & $\begin{array}{l}\text { Type of } \\
\text { variable }\end{array}$ & Definition and its measurements \\
\hline Age & Continuous & Age of the respondent in years \\
\hline Sex & Dummy & Sex: male $=1$, female $=0$ \\
\hline Education & Discrete & $\begin{array}{c}\text { Educational levels: illiterate }=1 \text {, read and write }=2 \text {, elementary school }=3 \text {, secondary school and } \\
\text { above }=4\end{array}$ \\
\hline Land size & Continuous & Land size under cultivated in hectare \\
\hline Faming experience & Continuous & Farmers year of experience in maize storage \\
\hline $\begin{array}{l}\text { Quantity of maize } \\
\text { stored }\end{array}$ & Continuous & Quantity of maize stored in quintal \\
\hline Training & Dummy & Postharvest loss and storage training taken by farmers: yes $=1$, no $=0$ \\
\hline Access of PICS & Dummy & PICS access to farmers: yes $=1$, no $=0$ \\
\hline Price of PICS & Discrete & Cost of PICS by farmers view: low $=1$, medium $=2$, high $=3$ \\
\hline Awareness on PICS & Dummy & Awareness of farmers on PICS storage: yes $=1$, no $=0$ \\
\hline $\begin{array}{l}\text { Chemical pesticide } \\
\text { effect }\end{array}$ & Dummy & Understanding the effect of chemical pesticides: yes $=1$, no $=0$ \\
\hline Annual income & Continuous & Farmers annual income in Ethiopian birr \\
\hline Extension services & Discrete & $\begin{array}{l}\text { Contact of extension agent with farmers: no contact at all }=0 \text {, once in a week }=1 \text {, once in two } \\
\text { weeks }=2 \text {, once in three weeks }=3 \text {, once in a month }=4 \text {, otherwise }=5\end{array}$ \\
\hline Credit access & Dummy & Farmers credit access: yes $=1$, no $=0$ \\
\hline
\end{tabular}

TABLE 2: Descriptive analysis results of categorical variables.

\begin{tabular}{|c|c|c|c|c|c|c|c|c|}
\hline \multirow{3}{*}{ Variables } & \multirow{3}{*}{ Categories } & \multicolumn{4}{|c|}{ Use of PICS bags } & \multirow{2}{*}{\multicolumn{2}{|c|}{ Total $(n=392)$}} & \multirow{3}{*}{$\chi^{2}$ test } \\
\hline & & \multicolumn{2}{|c|}{ User } & \multicolumn{2}{|c|}{ Nonuser } & & & \\
\hline & & Number & $\%$ & Number & $\%$ & Number & $\%$ & \\
\hline \multirow{2}{*}{ Sex } & Male & 189 & 96.4 & 179 & 91.3 & 368 & 93.8 & \multirow{2}{*}{$4.438^{* *}$} \\
\hline & Female & 7 & 3.6 & 17 & 8.7 & 24 & 6.2 & \\
\hline \multirow{4}{*}{ Marital status } & Single & 1 & 0.5 & 0 & 0 & 1 & 0.3 & \multirow{4}{*}{$7.951^{* *}$} \\
\hline & Married & 188 & 95.9 & 176 & 89.8 & 364 & 92.9 & \\
\hline & Divorced & 3 & 1.5 & 6 & 3.1 & 9 & 2.3 & \\
\hline & Widowed & 4 & 2 & 14 & 7.1 & 18 & 4.6 & \\
\hline \multirow{4}{*}{ Educational status } & Illiterate & 45 & 23 & 150 & 76.5 & 195 & 49.7 & \multirow{4}{*}{$116.481^{* * *}$} \\
\hline & Read and write & 123 & 62.8 & 44 & 22.4 & 167 & 42.6 & \\
\hline & Primary education & 26 & 13.3 & 2 & 1 & 28 & 7.1 & \\
\hline & Secondary and above & 2 & 1 & 0 & 0 & 2 & 0.5 & \\
\hline
\end{tabular}

*** and ${ }^{* *}$ significant at $P<0.01$ and $P<0.05$.

TABle 3: Descriptive analysis results of continuous variables.

\begin{tabular}{lcccccc}
\hline \multirow{2}{*}{ Variables } & \multicolumn{2}{c}{ User } & \multicolumn{2}{c}{ Nonuser } & \multicolumn{2}{c}{ Total $(n=392)$} \\
& Mean & Std. deviation & Mean & Std. deviation & Mean & St. deviation \\
\hline Age & 42.68 & 6.792 & 47.78 & 9.816 & 45.23 & 8.803 \\
Family size & 4.99 & 1.625 & 4.96 & 1.5 & 4.98 & 1.56 \\
Farming experience & 23.41 & 8.087 & 21.17 & 6.633 & 25.64 & 8.780 \\
Landholding size & 2.383 & 1.218 & 2.11 & 1.295 & 2.246 & 1.263 \\
Number of livestock (TLU) & 7.3 & 2.577 & 5.02 & 2.298 & 6.16 & -0.194 \\
\hline
\end{tabular}

*** and ${ }^{* *}$ are significant at $P<0.01$ and $P<0.05$.

observation of this study. The difference between mean livestock holdings of users and nonusers of Purdue improved crop storage bag was statistically significant, and users have more livestock's than nonusers. Conversion factors used were based on [16].
3.2. Institutional Support for the Use of PICS Bags. Access to extension carrier could be very essential detail of institutional assist wished via way of means of farmers to decorate the usage of agricultural technology in popular and advanced crop storage technology like PICS in particular. 
Development agents were assigned in all sample kebeles, and therefore, it is expected that sample farmers in the study area have an access to extension services through the DAs, attending field days and training. All sample households had been visited by development agents at least once a month, and most of the respondents (66.3\%) of the respondents have been visited once a month (Table 4). In addition to encouraging farmers to use improved technologies, training and demonstration days also play important role in creating linkages. Among the total number of respondents, $20.2 \%$ participated in training of PICS bag and participated on open the bag ceremony. About $38.3 \%$ of the user and $2 \%$ of the nonuser participated in training. The difference was statistically tested, and participation in PICS training was found to be significant at $1 \%$ level of significance $\left(\chi^{2}=79.9\right)$ (Table 4).

Credit is a crucial institutional service to finance poor farmers for input purchase and ultimately to adopt new technology. However, all farmers may not have access due to problems related to repayment, previous credit defaults, and collateral in order to get credit. The survey result indicated PICS users had better access to credit compared to nonusers. The difference is statistically significant at $1 \%\left(\chi^{2}=82.03\right)$ (Table 4).

\subsection{Smallholder Farmers Awareness about PICS Bags. As} shown in Table 5, most of the respondents from nonusers of PICS bags (54\%) have no any awareness about the overall nature and use of PICS bag, and as a result, they did not use it ever, while the rest of $46 \%$ of them have information and awareness about PICS bags, but they did not use it because of different reasons particularly due to the high price of the bag and its poor accessibility. This finding is in line with [17] whose findings revealed that less than $50 \%$ of farmers in his study area had not adopted improved storage systems since they were not aware of them. As we have observed and discussed in the study area, the extension work regarding the dissemination and adoption of PICS bags in the study area especially in Zalima and Wadra was very poor even the users of the PICS bags in this area were not well trained. It is evident that many households used the triple layer of the bags separately just after one year of use because they were perceived that the PICS bags are used only for one year. This finding is supported by the study of Okoedo and Onemoleas [18].

3.4. Farmers Perception on the Importance of PICS Bags. It is known that PICS bags have a significant importance in protecting stored maize damage from insect and in maintaining the quality of food for consumption and the surrounding environment by avoiding the application of chemical insecticide which has the potential poisoning substances in contaminating our food as well as the surrounding, resulting in different human health problems. As shown in Figure 3, the total respondents who were users and nonusers of the PICS bags around 57.9\% and 57.1\% were highly perceived as the technology protects the stored maize from insect damage and can maintain the quality of food and environment, respectively. Surprisingly, a large proportion of the respondents (37.2\% and 39.5\%) had no any awareness whether the technology protects insects and maintains food and environment quality, respectively (Figure 3).

\subsection{Motivating Factors to Use PICS Bags over Chemical} Insecticide. There are different motivating factors that trigger the community to adopt PICS bag technology in the study area. Besides other factors, increment of storage time without insect damage maintains food, seed, and environment quality from chemical substance poisoning. As shown in Figure 4, a majority of the respondents (75\% and 58\%) used PICS bags particularly to increase the shelf life of the stored maize without insect damage and to maintain their grain quality safe for consumption by avoiding chemical substance application on it, whereas only the small proportion of smallholder farmers (6\% and 5\%) used PICS bags for the purpose of maintain grain quality for next seed input and to make their environment safe enough by avoiding the application of insecticide in their storage. Therefore, this survey showed that a large number of users of PICS bags lacked awareness about the importance of PICS bags in reducing environmental pollution and in maintaining the quality of seed for future production.

3.6. Reasons of Nonusers for Not Using PICS Bags. The study also found out why nonusers of PICS bags did not use the PICS bags, in spite of the awareness of the technology by majority of them. Result presented in (Figure 5) showed that $51 \%$ of the respondents claimed that they did not participate and use the technology based on their perceived idea that the PICS bag is too costly. According to the information obtained from the local vendors and the community who already bought the bag, the present price of $43 \mathrm{ETB} / \mathrm{bag}$ is considered too high by most maize grower farmers in the study area. High costs of the bags appear to be the major reason for poor adoption of PICS bags technology. Based on the information obtained from the local vendor and Shayashone consultant, the bag manufacturing company and distributor are not willing for any reduction in retail price. Similarly, Moussa et al. [19] also found that the cost of the bags was cited as a key constraint to use the PICS bags by a large number of respondents.

In addition to the dearer price of the bag, lack of awareness of the farmers on technology was a significant factor in hindering the use of PICS bags. 54\% of the respondents had poor awareness about the importance of the bags even they did not hear about the technology at all in the study area (Figure 5). Farmer's awareness about the available PICS technology is vital to enhance the use of PICS bags. To adopt the newly introduced technologies, farmers need to be aware of the available technology as adoption is sometimes hampered not only by the inherent characteristics of the innovation but also by lack of awareness of the end users of the technologies [20]. The complaint on the poor accessibility of the PICS bags was reported by $7 \%$ of the respondents (Figure 5). This implied that farmers in the study area have no access of PICS bags by the nearby place and only one 
TABLE 4: Distribution of sample households by frequency of extension visits, attendance in PICS training, and credit access.

\begin{tabular}{|c|c|c|c|c|c|c|c|}
\hline \multirow{2}{*}{ Item } & \multicolumn{2}{|c|}{ User } & \multicolumn{2}{|c|}{ Nonuser } & \multicolumn{2}{|c|}{ Total } & \multirow{2}{*}{$\chi^{2}$ test } \\
\hline & Number & $\%$ & Number & $\%$ & Number & $\%$ & \\
\hline \multicolumn{8}{|l|}{ Extension contact } \\
\hline Once a month & 108 & 55.1 & 152 & 77.6 & 260 & 66.3 & \multirow[t]{5}{*}{$22.2^{* * *}$} \\
\hline Twice a month & 64 & 32.7 & 31 & 15.8 & 95 & 24.2 & \\
\hline Three times a month & 16 & 8.2 & 9 & 4.6 & 25 & 6.4 & \\
\hline More than three times a month & 8 & 4.1 & 4 & 2 & 12 & 3.1 & \\
\hline No visit & 0 & 0 & 0 & 0 & 0 & 0 & \\
\hline PICS training & & & & & & & \multirow[t]{3}{*}{$79.9^{* * *}$} \\
\hline Yes & 75 & 38.3 & 4 & 2 & 79 & 20.2 & \\
\hline No & 121 & 61.7 & 192 & 98 & 313 & 79.8 & \\
\hline Credit access & & & & & & & \multirow[t]{3}{*}{$82.03^{* * *}$} \\
\hline Yes & 134 & 68.4 & 44 & 22.7 & 178 & 45.6 & \\
\hline No & 62 & 31.6 & 150 & 77.3 & 212 & 54.4 & \\
\hline
\end{tabular}

${ }^{* * *}$ : significant at $P<0.01$.

TABle 5: Respondents' awareness about PICS bags.

\begin{tabular}{cccccccc}
\hline \multirow{2}{*}{ Item } & \multicolumn{2}{c}{ User } & \multicolumn{2}{c}{ Nonuser } & \multicolumn{2}{c}{ Total } \\
& & No. & $\%$ & No. & $\%$ & No. & $\%$ \\
\hline & & Yes & 196 & 100 & 90 & 45.9 & 286 \\
Have you awareness about PICS bags? & No & 0 & 0 & 106 & 54.1 & 106 & 27 \\
& Total & 196 & & 196 & & 392 \\
\hline
\end{tabular}

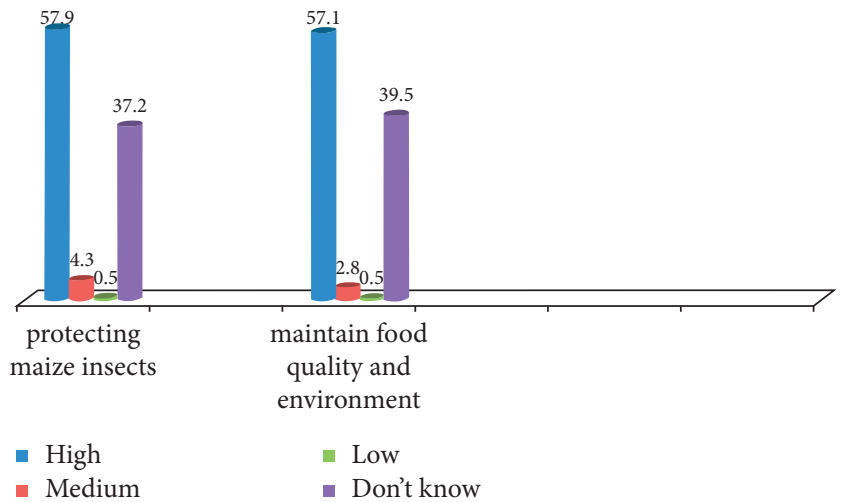

FIgURE 3: Percentage of respondents' awareness on the importance of PICS bags.

vendor throughout the district. This is in line with findings of Moussa et al. [19].

3.7. Determinants of the Use of PICS Bags. The model was assessed for its goodness of fit by examining how well the model classifies the observed data (in the classification table) or by examination of how likely the sample results are, given the estimates of model parameters [21]. The result indicates that (the model chi-square value) the parameters included in the model taken together were significantly different from zero at less than 1 percent level of significance. The value of chi-square $\left(\chi^{2}=395.812\right)$ indicates also the goodness of fitted model (Table 6). Maximum likelihood was used to estimate the parameters of the variables that are expected to influence the use of PICS bags. In the model, 15 potential continuous

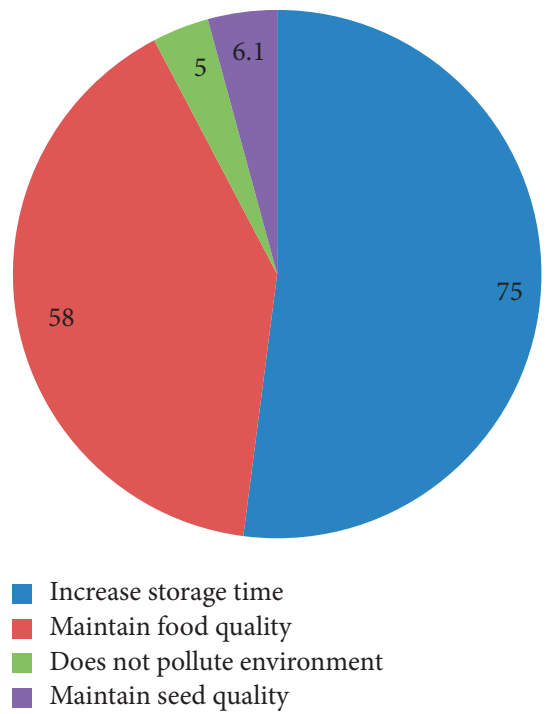

FIgURE 4: Motivating factors to use PICS bags over chemical insecticide (\%).

and discrete variables were entered; out of the total of these explanatory variables, only 9 variables were found to be significantly influencing the use of PICS bags. Variables found to be significant included sex, education, responsibility in the community, PICS training, awareness on the effect of chemical on health and environment, awareness of PICS, PICS access, and price of PICS which were found to be significant at $1 \%$, and also total annual income was found to be significant at $5 \%$ probability level (Table 6). However, the remaining six variables, namely, age, farming experience, farm size, extension contact, access/use of credit, and 


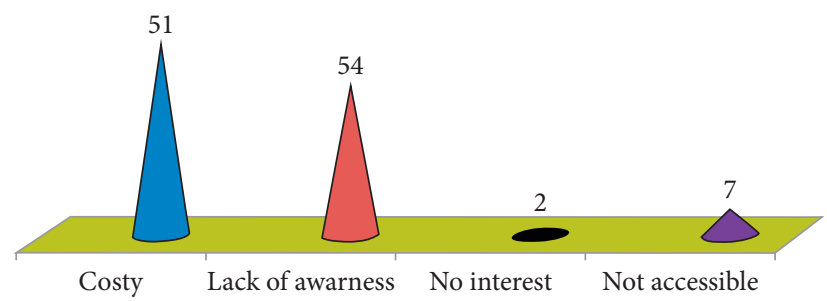

Figure 5: Reasons of nonusers for not using PICS bags (\%).

TABLE 6: The maximum likelihood estimates of the binary logistic regression model.

\begin{tabular}{|c|c|c|c|c|c|c|c|}
\hline \multirow{2}{*}{ Variables } & \multirow{2}{*}{$\mathrm{B}$} & \multirow{2}{*}{ S.E. } & \multirow{2}{*}{ Wald } & \multirow{2}{*}{ Sig. } & \multirow{2}{*}{ Exp. (B) } & \multicolumn{2}{|c|}{ 95\% C.I. for Exp. (B) } \\
\hline & & & & & & Lower & Upper \\
\hline Sex & 2.439 & 0.913 & 7.134 & $0.008^{* * *}$ & 0.087 & 0.015 & 0.522 \\
\hline Age & -0.068 & 0.058 & 1.383 & 0.24 & 0.935 & 0.835 & 1.046 \\
\hline Education level & 1.595 & 0.479 & 11.109 & $0.001^{* * *}$ & 4.928 & 1.929 & 12.59 \\
\hline Farm exp & 0.018 & 0.06 & 0.087 & 0.769 & 1.018 & 0.904 & 1.146 \\
\hline Social responsibility & 2.296 & 0.561 & 16.745 & $0.000^{* * *}$ & 9.931 & 3.307 & 29.822 \\
\hline Land size & -0.311 & 0.334 & 0.865 & 0.352 & 0.733 & 0.381 & 1.41 \\
\hline Total income & 0.015 & 0.026 & 4.548 & $0.033^{* *}$ & 1.015 & 0.807 & 1.138 \\
\hline Credit access & 0.644 & 0.533 & 1.462 & 0.227 & 1.904 & 0.671 & 5.407 \\
\hline Extension contact & 0.463 & 0.409 & 1.28 & 0.258 & 0.629 & 0.282 & 1.403 \\
\hline PICS training & 2.629 & 0.729 & 13.014 & $0.000^{* * *}$ & 13.854 & 3.322 & 57.784 \\
\hline Chemical effect & 1.236 & 0.458 & 7.291 & $0.007^{* * *}$ & 3.441 & 1.403 & 8.44 \\
\hline Awareness PICS & 3.307 & 0.805 & 16.882 & $0.000^{* * *}$ & 27.308 & 5.638 & 132.259 \\
\hline PICS access & 3.131 & 0.726 & 18.603 & $0.000^{* * *}$ & 22.887 & 5.518 & 94.931 \\
\hline PICS price & -2.054 & 0.822 & 6.24 & $0.012^{* * *}$ & 7.796 & 1.556 & 39.049 \\
\hline Maize stored & 0.013 & 0.023 & 0.325 & 0.569 & 1.013 & 0.968 & 1.06 \\
\hline Constant & -3.706 & 1.939 & 3.653 & $0.05^{* *}$ & 0.025 & & \\
\hline
\end{tabular}

Pearson chi-square: $395.812^{* * *},-2 \log$ likelihood: 142.029 , overall prediction of the model ${ }^{1}: 94.85$, sensitivity ${ }^{2}: 95.8$, specificity ${ }^{3}: 93.9$, sample size: 392 households, ${ }^{* * *}$ and ${ }^{* *}$ indicate significance at $1 \%$ and $5 \%$ level respectively. 1: the success of prediction of the model based on a $50 \%$ probability classification table. 2: correctly predicted households that use PICS bags on a 50\% probability classification. 3: correctly predicted households that did not use PICS bags based on 0.5 cut point probability table, source: binary logit model output.

quantity of maize stored were found to have insignificant impact on farmers' use of PICS bags in the study area. With the above brief background, the effect of the significant explanatory variables on the adoption of PICS bags was discussed as follows.

3.7.1. Educational Level of the Household Head. This explanatory variable showed a positive relationship with the use of improved crop storage technologies (PICS bags). The respondents who are educated are $4.928 \%$ more likely to use PICS bags than illiterate respondents. Education was found to affect the use of PICS bags positively and significantly at $1 \%$ significance level. Similar results were found in $[22,23]$ which showed that education enables farmers too easily understand and recognize the use of PICS bags, the problem of postharvest loss, and be able to change in to practice the knowledge and skill they obtained. Another study undertaken by Soni et al. [24] in Sagar district using binary logit model also stated that there was a positive association between the level of education of farmers and the extent of adoption of modern storage methods. 100 farmers' were interviewed, and results showed that lack of knowledge was a major obstacle in adopting improved storage systems within the region.
3.7.2. Sex of the Household Head. Based on the result of the model, sex was found to have positive and statistically significance at $1 \%$ significant level. The results of the model revealed that male-headed households were $8.7 \%$ more probable to use PICS bags than female-headed households. This could be attributed to various reasons, which could be the problem of economic position of female-headed households, including shortage of labor, limited access to information, and required inputs due to social position. Therefore, a result indicated that the male-headed households are better users of PICS bags. This may be due to relatively better access of male-headed households to information and agricultural resources than female household heads. The result is in line with the finding of similar studies $[25,26]$.

3.7.3. Awareness of PICS. It is positive and statistically significant at $1 \%$ significant level. This result revealed that those households who were aware or had awareness about PICS bags were 27 times more likely to use PICS bags than those households who had not awareness about this technology. This suggests that the awareness of farmers for the PICS technology was used as an information dissemination tool, and this leads to higher probability of using the PICS 
bag technology than respondents with no awareness about PICS bags. This finding is consistent with the findings of [27] who found that awareness was an important factor influencing individual behavior to adopt technology.

3.7.4. PICS Training. In the model, we observe that the coefficient for PICS training is positive and statistically significant at $1 \%$. These results indicate that farmers who participated in the PICS village-level demonstration and training were 13.8 times more likely to use the PICS bag technology than those who were not involved in the villagelevel demonstrations and training. The justification is due to improving their understanding and awareness of importance of PICS in protecting maize damage from insects and maintaining the food quality as well as protecting environment from pollution by reducing chemicals or insecticide application in the storage. This result confirms the conclusions of $[28,29]$, which support the idea that active participation or attendance in field demonstrations and training has a significant impact on the adoptability of technology particularly in developing countries. This is in line with findings of Wekesa et al. [30], which indicated that farmers who had been trained were greater adopters of improved storage systems.

3.7.5. Social Position. It was found to be influence use of PICS bags positively and significantly at $1 \%$ significant level. Household head who was involved in various positions and responsibilities was 9.9 times more likely to use PICS bags than households who have no any social responsibilities or position. This is because farmers who are involved in different administrative, religious, and other matters in the community are more exposed to new information and technologies. The participation of farmers in leadership of social organization will also increase skill and awareness on the existence and importance of recent technology through the provision of necessary information, knowledge, and discussion that assist farmers/traders to use the innovation to better their lots. Therefore, it is expected that a household head who is involved in various positions is more likely to use improved crop storage technologies. This finding is also consistent with Michael Bolaji [31]. And also, Yitayal [23] found a positive relationship between social position and the decision to use conservation technologies.

3.7.6. Annual Income. The coefficient of income was positive and statistically significant at $5 \%$ level; this implies that as the income of the households increased by 1 ETB birr, the likelihood of using PICS bag technology increased by 1.015 factors. This is because with more income the farmers can invest more to increase their output. Farmers with higher income or production levels may have more resources and a higher need of good storage methods and, thus, are more likely to adopt the triple-bag technology. This finding is consistent with the findings of Michael Bolaji [31].
3.7.7. Access to PICS Bags. This variable was found to be positively and significantly associated with the use of PICS bags at $1 \%$ level of significance, and the result confirms the prior hypothesis. The odds ratio of 22.89, other things kept constant, implies that the probability of using PICS bags increases by the factor of 22.89 as the household's access to a possibility of getting the bags in the nearest area increases by a unitary value as compared to those who do not have an access. As the availability of PICS bag supply at the harvesting time increase, farmers' use of PICS bags would be enhanced. On the contrary, if PICS bags supply are not adequate at the time of harvesting, farmers may use other storage technologies by applying insecticides on their maize. Inadequate number and distal of vendors is the major constraint faced by farmers to easily access and use, and therefore, disconnection in information flow and supply chain of PICS bags is created between the manufacturer or trader and maize producer households in the study area. Jokthan and Sanni [32] also found similar result. This matches the findings of Soni and Kurmvanshi. [33] for poor adoption of improved storage systems in India, where 18.5\% complained of high costs of the improved systems and nonavailability of the technology. In the study by Moussa et al. [19], lack of local availability of bags was the most often cited reason for not using PICS bags. This analysis supports hypothesis that lack of local availability of the bags is the most important factor in the adoption decision.

3.7.8. Price of PICS Bags. This variable was found to influence the use of PICS bag negatively and significantly at $1 \%$ level of significance. The logistic regression model result revealed that, by holding other factors constant, the probability of using PICS bags by households who perceived the price as expensive was 7.796 times less likely to use PICS bags than those households who perceived the price of the bag which were as cheap. The price of the PICS which was $43 \mathrm{birr} / \mathrm{bag}$ is considered too high by most farmers and households. It is possible to suggest that the high price of the bags appears to be the major reason for poor adoption by farmers. The bag company is not willing to any reduction in retail price associated with possible mass production and considered as one crucial factor for farmers' decision to use PICS bags [32]. Similarly, the authors of [18] revealed that nonavailability and high cost of improved storage systems also account for farmers' nonadoption of storage systems.

3.7.9. Perceived Effect of Chemical Pesticide on Health and Environment. It is positive and statistically significant at $1 \%$ indicating that those farmers who were perceived as using insecticide has negative impact on their food or health and environment were more likely to adopt this triple-bag technology. Therefore, the result of the model implied that the respondents who are aware of the impact of insecticides on health and environment were 3.441 times more likely to adopt the PICS bag technology than those who did not understand the impact. These farmers may possibly be on the search for improved storage techniques and are, thus, more likely to use the triple-bag technology if available. 
There has been increased awareness of health risks associated with insecticide use which may be the factor driving farmers' search for alternative storage technologies. Earlier adoption studies omitted farmers' perception of technology attributes, and there might have biased the results of factors conditioning adoption decisions against this variable. But nowadays, adoption studies [34] considering farmers' perception of technology attributes have found that these attributes condition the adoption choices of farmers. Farmers have subjective preferences for technology characteristics [28], and this could play major roles in adoption.

\section{Conclusion and Recommendation}

Storage loss is perhaps the most persistent issues of maize production in Ethiopia, and it is more aggravating than it was ever previously. The majority of the respondents from nonusers of PICS packs (54\%) have no any mindfulness about the general nature and utilization of PICS sack, and thus they did not utilize it ever, while the remainder of $46 \%$ of them have informed about PICS sacks yet they did not utilize; this is a result of various reasons especially because of the excessive cost of the sack and its poor accessibility. The extension work and awareness creation regarding PICS bags technology in the study area were very poor even the users of the PICS bags in study area were not well trained and empowered. It is obvious that large households utilized the triple layer bags independently soon after one year of utilization since they were seen that the PICS packs are utilized distinctly for one year. Similarly, the result of the model indicated that educational level, sex, awareness on PICS bags, training about PICS bags, accessibility of the bags, perception on the effect of chemical, social responsibility, and total income of the household were found to positively and significantly affect farmers' decision to use PICS bags, whereas price of PICS affected negatively and significantly.

Based on the findings, the following recommendations are made:

(i) In the study area, large number of farmers had no awareness about PICS bags. Therefore, awareness creation is important through strengthening the extension work, sensitizing farmers through demonstration (open the bag ceremony) and mass media like radio, more training needs to be offered to maize farmers, and extension workers to improve the farm households' technical know-how.

(ii) Manufacturer had to better produce the bag with big size to reduce theft and should have to make it better by strong material which is not easily teared and attacked by rodents. There is also scarcity of bags so it is better to increase accessibility of the bag by near areas, i.e., ready market (vendor) should be developed.

(iii) To improve access, various bag sizes $(25 \mathrm{~kg}, 50 \mathrm{~kg}$, $100 \mathrm{~kg}$, etc) should be introduced to the market to suit different categories of users (small, medium, and large farmers) and make these technologies available to smallholder farmers.

\section{Abbreviations}

ACSI: Amhara Credit and Saving Institution

CC: $\quad$ Contingency coefficient

CSA: Central Statistical Agency

ETB: Ethiopian birr

FAO: $\quad$ Food and Agriculture Organization

Ha: Hectare

GDP: Gross domestic product

IITA: International Institute of Tropical Agriculture

NGO: Nongovernmental Organizations

NRI: Natural Resources Institute

PHL: Postharvest loss

PICS: $\quad$ Purdue Improved Crop Storage

TOT: Training of trainers

SG-2000: Sasakawa Global-2000

VIF: Variance inflating factors.

\section{Data Availability}

The datasets used during the current study are available from the corresponding author on reasonable request.

\section{Ethical Approval}

Ethical clearance was obtained from ethical clearance review committee of Bahir Dar University. To ensure confidentiality, the names of the study subjects were not written on the questionnaire and did not share with anyone else. All incomplete questionnaires were considered as nonresponse rate.

\section{Consent}

The purpose of the study was explained to the study participants, and a written informed consent was obtained from participants to confirm whether they were willing to participate or not. The data collectors collected the information after obtaining verbal consent from each participant. Respondents were informed that they can refuse or discontinue participation at any time they want, and they were also informed that they can ask anything about the study.

\section{Conflicts of Interest}

The authors declare no conflicts of interest.

\section{Authors' Contributions}

TKM participated in the design, data collection, data analysis, and interpretation. BYW also participated in the analysis, interpretation, and drafting of the manuscript. All authors read and approved the final manuscript.

\section{Acknowledgments}

The authors would like to acknowledge their data collectors and study participants. 


\section{References}

[1] G. Ibro, M. C. Sorgho, A. A. Idris, B. Moussa, D. Baributsa, and J. Lowenberg-DeBoer, "Adoption of cowpea hermetic storage by women in Nigeria, Niger and Burkina Faso," Journal of Stored Products Research, vol. 58, pp. 87-96, 2014.

[2] Food and Agriculture Organization of the United Nations and Natural Resources Institute, "Missing food: the case of postharvest grain losses in sub-Saharan Africa," Report No. 60371-AFR, The International Bank for Reconstruction and Development/The World Bank, Washington, DC, USA, 2011.

[3] T. Tefera, "Post-harvest losses in African maize in the face of increasing food shortage," Food Security, vol. 4, no. 2, pp. 267-277, 2012.

[4] H. G. Abebe and H. Bekele, "Farmers' post-harvest grain management choices under liquidity constraints and impending risks: implications for achieving food security objectives in Ethiopia," in Proceedings of the International Association of Agricultural Economists Conference, pp. 12-18, GoldCoast, Australia, 2006.

[5] J. M. Songa and W. Rono, "Indigenous methods for bruchid beetle (Coleoptera: bruchidae) control in stored beans (Phaseolus vulgaris L.)," International Journal of Pest Management, vol. 44, no. 1, pp. 1-4,, 1998.

[6] L. L. Murdock, D. Seck, G. Ntoukam, L. Kitch, and R. E. Shade, "Preservation of cowpea grain in sub-Saharan Africa-bean/cowpea CRSP contributions," Field Crops Research, vol. 82, no. 2-3, pp. 169-178, 2003.

[7] K. Hell, K. E. Ognakossan, A. K. Tonou, Y. Lamboni, K. E. Adabe, and O. Coulibaly, "Maize stored pests control by PICS-bags: technological and economic evaluation," in Proceedings of the 5th World Cowpea Conference, Saly, Senegal, October 2010.

[8] A. Aleminew, "Market chain analysis of red pepper: the case of Burie district, west Gojjam zone, Amhara national regional state, Ethiopia," M.Sc. thesis, School of Graduate Studies of Haramaya University, Dire Dawa, Ethiopia, 2010.

[9] Burie District Office of Agriculture, Unpublished Office Report, Burie District Office of Agriculture, Burie, Ethiopia, 2016.

[10] T. Yamane, Statistics, an Introductory Analysis, Harper \& Row, New York, NY, USA, 2nd edition, 1967.

[11] R. S. Pindyck and D. L. Rubinfeld, Econometric Models and Economic Forecasts, McGraw Hill Book Co., New York, NY, USA, Second edition, 1981.

[12] G. H. William, Economic Analysis, New York University, Macmillan Publishing Company, New York, NY, USA, 1991.

[13] N. D. Gujarati, Basic Econometrics, McGraw-Hill, New York, NY, USA, Third edition, 1995.

[14] D. N. Gujarati, Basic Econometrics, McGraw-Hill, New York, NY, USA, 4th edition, 2003.

[15] Central Statistical Agency, Agricultural Sample Survey for 2013/14: Report on Area and Production of Major Crops for Private Peasant Holdings, Meher Season, Statistical Bulletin No 532, May 2014, Central Statistical Agency, Addis Ababa, Ethiopia, 2013.

[16] H. Strock, B. Adnew, B. Emana, A. Borowiecki, and S. W. Hawariat, Farming Systems and Farm Management Practices of Smallholders in the Hararghe Highlands, Vol. 2, Wissenschaftsverlag Vauk, Kiel, Germany, 1991.

[17] N. Khan and J. D. Keatinge, "Awareness and level of adoption of agricultural technologies in the remote areas of NWFP," Sarhad Journal of Agriculture, vol. 16, no. 2, pp. 217-226, 2000.

[18] O. Okoedo and E. A. Onemoleas, "Impact of the agricultural development programme (ADP) activities in arable crop production on rural poverty alleviation in Edo state, Nigeria," Ph.D. thesis, University of Benin, Benin City, Nigeria, 2009.

[19] B. Moussa, T. Abdoulaye, O. Coulibaly, D. Baributsa, and J. Lowenberg-DeBoer, "Adoption of on-farm hermetic storage for cowpea in West and central Africa in 2012," Journal of Stored Products Research, vol. 58, pp. 77-86, 2012.

[20] S. Asfaw, "Estimating welfare effect of modern agriculture technologies: a micro-perspective from Tanzania and Ethiopia "Ten Years of War against Poverty"” Chronic Poverty Research Centre, Addis Ababa, Ethiopia, 2011.

[21] D. w. Hosmer and S. Lemeshow, Applied Logistic Regression, University of Massachusetts and Amberst, Wiley-Inter Science Publication, New York, NY, USA, 1989.

[22] C. A. Ervin and D. E. Ervin, "Factors affecting the use of conservation practices. Hypothesis, evidence, and policy implications," Land Economics, vol. 58, no. 3, pp. 97-307, 1982.

[23] A. Yitayal, "Determinants of use of soil conservation measures by small holder farmers; in Gimma zone, Dedo district," pp. 65-82, School of Graduate Studies of Alemaya University, Dire Dawa, Ethiopia, 2004, M.S. thesis.

[24] S. N. Soni, R. K. Pathak, and R. R. Kashikar, "Socio-economic studies to analyze constraints in the adoption of modern technology by various groups in Sagar district, Madhya Pradesh," Crop Research (Hisar), vol. 19, no. 2, pp. 353-356, 2000.

[25] M. Enki, "Determinants of adoption of soil conservation practices in central high lands of Ethiopia: the case of three districts of Salale," M.S. thesis, School of Graduate Studies of Alemaya University, Dire Dawa, Ethiopia, 2000.

[26] A. Techane, "Determinants of fertilizer adoption in Ethiopia: the case of major cereal producing areas," M.S. thesis, School of Graduate Studies of Haramaya University, Dire Dawa, Ethiopia, 2002.

[27] A. Mengist, "Factors Influencing adoption of soil conservation practices in south gondar zone: the case of Farta district," M.S. thesis, School of Graduate Studies of AlemayaUniversity, Dire Dawa, Ethiopia, 2003.

[28] A. A. Adesina, D. Mbila, G. B. Nkamleu, and D. Endamana, "Econometric analysis of the determinants of adoption of alley farming by farmers in the forest zone of southwest Cameroon," Agriculture, Ecosystems \& Environment, vol. 80, no. 3, pp. 255-265, 2000.

[29] P. N. Ramji, K. R. Sharma, and G. B. Thapa, "Adoption of agroforestry in the hills of Nepal: a logistic regression analysis," Agricultural Systems, vol. 72, no. 3, pp. 177-196, 2002.

[30] E. Wekesa, W. Mwangi, H. Verkuijl, K. Danda, and H. De Groote, "Adoption of maize production technologies in the coastal lowlands of Kenya," Miscellaneous Reports 56109, CIMMYT, Mexico City, Mexico, 2003.

[31] A. Michael Bolaji, "Potential impact analysis of Purdue improved cowpea storage technology on income of users in north central Nigeria," pp. 81-82, Ahmadu Bello University, Zaria, Nigeria, 2014, Thesis Submitted to the School of Postgraduate Studies.

[32] G. Jokthan and A. Sanni, "An analysis of triple bag intervention for cowpea storage in Nigeria," in Proceedings of the Research into (Use) Workshop, Abuja, Nigeria, 2011.

[33] S. N. Soni and S. M. Kurmvanshi, "Technological status (adoption pattern) of soybean cultivation in district Sagar of Madhya Pradesh," Crop Research (Hisar), vol. 18, pp. 150-154, 1999.

[34] N. Wubeneh, "Farm-level adoption of new sorghum technologies in Tigray Region, Ethiopia," M.S. thesis, Purdue University, West Lafayette, IN, USA, 2003. 